\title{
Acute intussusception in adults; study of two observations at the Friendship Hospital Sino-Guinean in Kipe
}

Camara Soriba Naby ${ }^{*}$, Keita Ahmed Momzonba ${ }^{2}$, Kouyaté Adama ${ }^{3}$, Sylla Ousmane Soriba ${ }^{1}$, Sylla Fatoumata $^{3}$, Souare Ibrahima Sory ${ }^{4}$, Traore Eliza ${ }^{4}$, Camara Mohamed ${ }^{1}$ Sidibé Mamady ${ }^{1}$, Sylla Mohamed lamine ${ }^{4}$, Haidara Cherif ${ }^{4}$, Bangoura Aboubacar Makhissa ${ }^{5}$, Toure Aboubacar 6

${ }^{1}$ Department of visceral surgery, Friendship Hospital Sino Guinean of kipe. Faculty of Sciences and Techniques of Health, Gamal Abdel Nasser University of Conakry. Conakry, Guinea.

${ }^{2}$ Department of Anatomy Pathology, Friendship Hospital Sino Guinean of kipe. Faculty of Sciences and Techniques of Health, Gamal Abdel Nasser University of Conakry. Conakry, Guinea.

${ }^{3}$ Department of Medical Imaging Department, Sino Guinean Friendship Hospital Hospital. Faculty of Sciences and Techniques of Health, Gamal Abdel Nasser University of Conakry. Conakry, Guinea

${ }^{4}$ Department of Neurosurgery, Hospital of the Guinean Sino Friendship Hospital. Faculty of Sciences and Techniques of Health, Gamal Abdel Nasser University of Conakry. Conakry, Guinea.

${ }^{5}$ Department of medical and surgical emergencies, Hospital of the Guinean Sino Friendship Hospital. Faculty of Sciences and Techniques of Health, Gamal Abdel Nasser University of Conakry. Conakry, Guinea

${ }^{6}$ Department of General Surgery, Ignace Deen National Hospital, Faculty of Health Sciences and Techniques, Gamal Abdel Nasser University of Conakry. Conakry, Conakry, Guinea.

*Corresponding Author: Camara Soriba Naby, Department of visceral surgery, Friendship Hospital Sino Guinean of kipe. Faculty of Sciences and Techniques of Health, Gamal Abdel Nasser University of Conakry. Conakry, Guinea.

Received date: January 04, 2021; Accepted date: March 01, 2021; Published date: March 05, 2021

Citation: Camara S Naby, Keita A Momzonba, K Adama, Sylla O Soriba, S Fatoumata et al. (2021) Amoebiasis of the Penis: A Review and Update. Journal of Clinical Surgery and Research. 2(1) DOI:10.31579/2768-2757/003

Copyright: (C2021 Camara Soriba Naby, This is an open-access article distributed under the terms of the Creative Commons Attribution License, which permits unrestricted use, distribution, and reproduction in any medium, provided the original author and source are credited.

\section{Abstract}

Aim: Th study aim to make our contribution to the study of intussusception in adults, rare pathology in adults, acute intussusception also called (AII) refers to penetration of an intestinal segment into the underlying segment, by turning into a glove finger (invagination roll).

The aim of this work is to report two cases of acute intussusception in adults in the surgical department of the Sino-Guinean friendship hospital in kipe. Republic of Guinea.

Material and Method: This is a prospective two-year study, running from October 1, 2018 to September 30, 2020 Inclusive. All patients admitted for operated for acute intestinal invagination, whose age is between 25 and 50 years were included in our study. The operative specimen was analyzed anatomo pathologically after fixation with 10 percent formalin.

Clinical presentation: It concerned a man and a woman, in both cases the localization was ileal. Treatment was surgical and consisted of ileal resection followed by end-to-end ileoileale anastomosis in two planes. The operative consequences were simple.

Conclusion: Acute intussusception in adults is rare, the symptoms are noisy.

Keys Word: acute intussusception; adult; cytopathology; sino-guinean hospital

\section{Introduction}

Intussusception occurs when a segment of the intestine and its mesentery enter and become trapped in the downstream intestine. This incarceration leads to suffering of the intestine and the mesentery (nerves, blood vessels, lymphatics) 1. In surgical practice, intussusception in adults is rare, moreover, we report two cases in the service of visceral surgery at the Sino-Guinean friendship hospital in Kipe, Republic of Guinea.

\section{Materials and Method}

We carried out a 2-year descriptive prospective study from October 1, 2018 to September 30, 2020 inclusive. It involved a man and a woman. Included in the study were all patients operated on for intussusception whose diagnosis was made pre-operatively or intraoperatively and fulfilling the eligibility criteria. The sex ratio was 1 . The mean age of our patients was 38 years with extremes of 35 to 42 years. All our patients 
underwent the preoperative workup, the abdomen without preparation, the ultrasound and the barium enema.

The departments of visceral surgery and the anatomy and pathological cytology laboratory of the Sino-Guinean friendship hospital in kipe.

Immediately after surgical resection of the operative part, deposited in the laboratory without fixation in the fresh state.

We immediately proceeded to fixation in 10 percent formalin before macroscopy. After day's fixation, we proceeded to the gross examination.

\section{Clinical Presentation}

\section{Observation 1}

Mrs. K, C, a 39-year-old trader, was admitted to our emergency facility on September 23, 2020 for diffuse abdominal pain in the umbilical peri region, progressing for 3 days, accompanied by vomiting of food, stopping materials and gas.

The patient were caesarized on July 07, 2020 and is known to be diabetic under treatment.

Clinical examination found a supple abdomen with a defense localized only in the right iliac fossa, and in the periumbilical region also a palpable renitant, mobile, painful mass of the right iliac fossa. The digital rectal examination revealed a free anal margin a normal tonic anal sphincter a rectal bulb containing normal-looking stools, a painful and bulging Douglas-fir

The unprepared abdomen had shown greater hydro-aeric levels than central highs. The patient was conditioned followed by the placement of solutions with alternation of ringer lactate and dirty serum. We did not use the glucose serum because of his diabetic history. The diagnosis of acute bowel obstruction was made. Antibiotic treatment (metronidazole $1.5 \mathrm{~g} / 24 \mathrm{~h}$, amoxicillin $3 \mathrm{~g} / 24 \mathrm{~h}$ ), and anti-inflammatory treatment based on diclofenac $150 \mathrm{mg} / 24 \mathrm{~h}$ were instituted. The patient was observed in hospital during the observation period the vomiting resumed with a noticeable change in general condition followed by excruciating pain. The blood test showed hyper leukocytosis with polynuclear neutrophils. Blood sugar was $1.89 \mathrm{~g} / \mathrm{l}$. The unprepared abdomen image revealed clearcentered para-vertebral and pelvic opacities. The barium enema revealed a mass in the ascending colon and the ileocecal angle. The symptomatology took an evolution of type occlusion by clamps because of operative scar of cesarean section. We had performed a laparotomy on $09 / 24 / 2020$. At the opening we had demonstrated an ileoileal intussusception located at $20 \mathrm{~cm}$ from the ileo-cecal angle. Drain into the right Douglas-fir, then to the wall closure plan by plan with the dressing. The post-operative consequences were simple.

\section{Observation 2:}

Mr. K S., a Chinese expert aged 42, admitted to our center on 01/18/2019 for consultation, for abdominal pain and a feeling of heaviness in the right iliac fossa and hypogastrium, evolution about 3 days.

Clinical examination revealed a large mobile swelling, of a mole consistency with an irregular outline, dull on palpation. On admission the warning signs were mainly abdominal pain and a mass located in the right iliac fossa, not adhering to the deep plane. All evolving over about 2 days

Abdominopelvic ultrasound revealed a mass at the expense of the cecum and revealed a well-individualized right colon tumor. The unprepared abdomen showed clear-centered calcium opacities right para-vertebral and bilateral pelvic lines suggestive of bladder schistosomiasis. The barium enema presented an image of a right colonic mass with arrest of barite flakes. A laparotomy was performed on 09/24/2020. It showed an ileo-ileal invagination located $30 \mathrm{~cm}$ from the ileocecal angle. The intussusception tube was resected, and the colonic stump closed. A right ileostomy was made, followed by lavage and drainage of the peritoneal cavity. The reestablishment of the intestinal continuity by ileo-ileal endto-end took place 4 weeks later. The operative consequences were simple. The discharge from the hospital took place on 08/10/2020. Pathological examination revealed visible necrosis in the pathological results (figures 5 and 6)
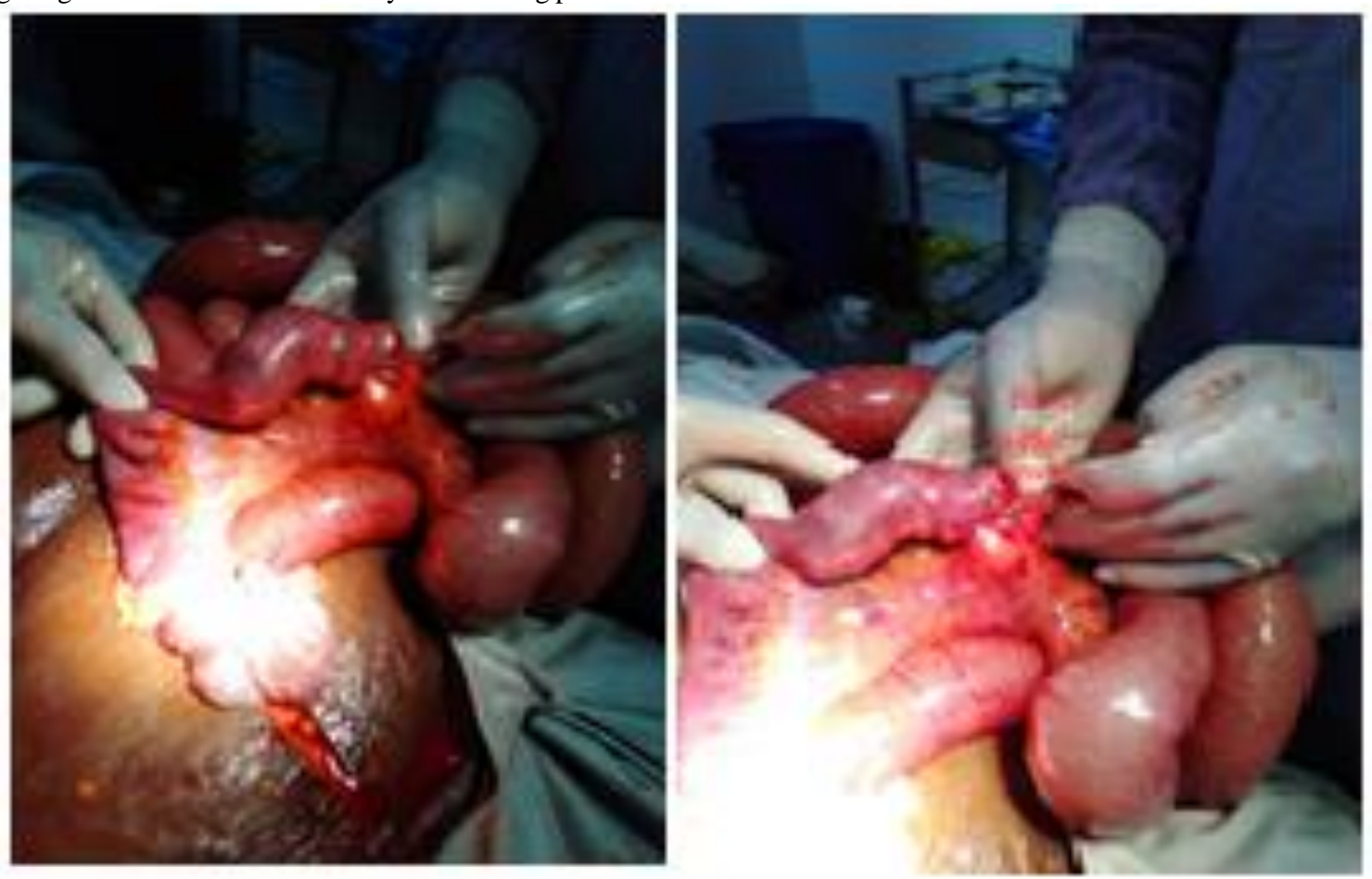

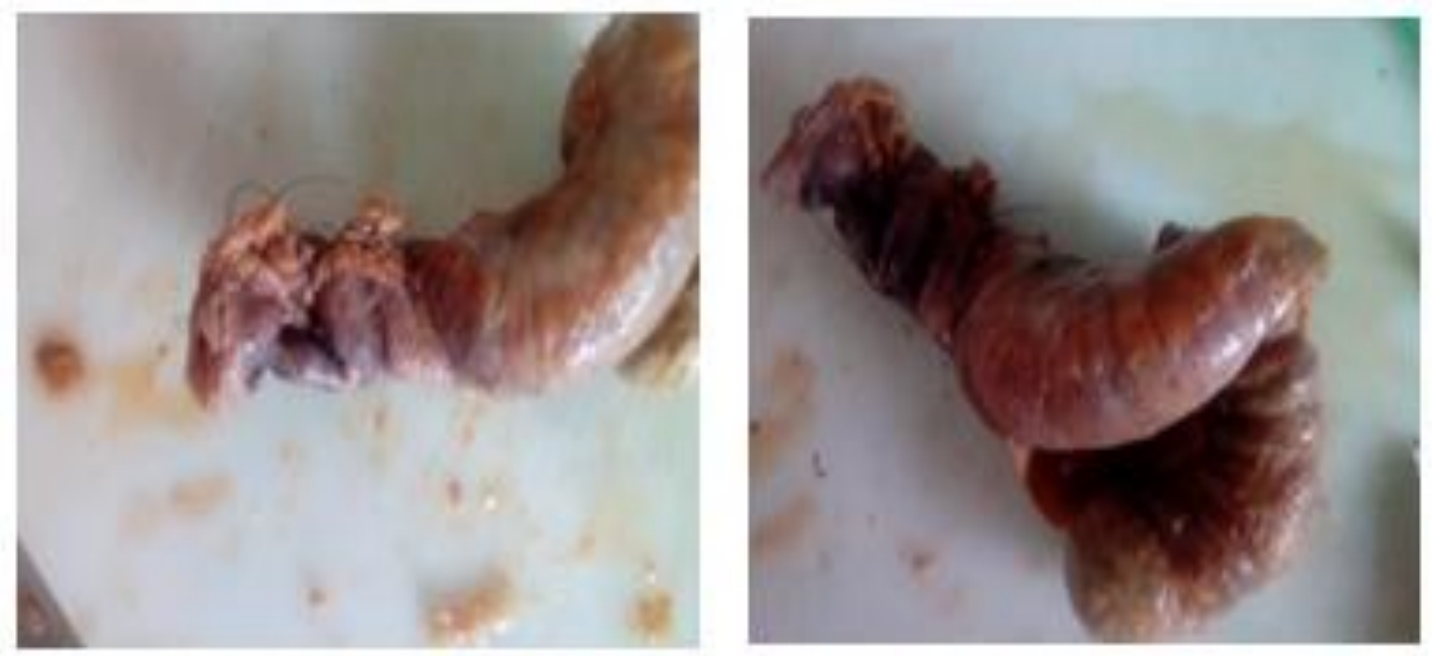

Figure 3

Figure 4

\section{Macroscopic views}

The sausage shows a segmental lesion of the head of the sausage entrained part of the mesentery which is compressed between the head and the sheath, occupying $14 \mathrm{~cm}$. The invagination area was located $4 \mathrm{~cm}$ from the

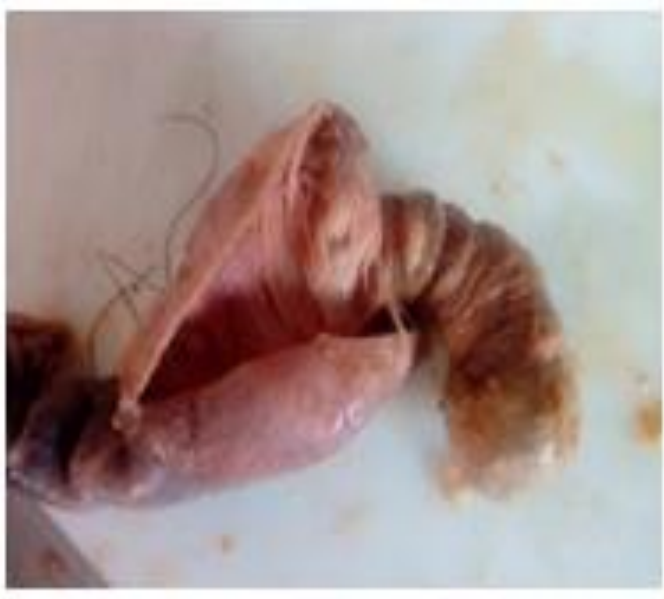

Figure 5 proximal area. Ileal lumen without ulceration. The invaginated part is narrowed alternately with a dilated area. The cut to interested.

The wall of intussusception is thickened, yellowish-red

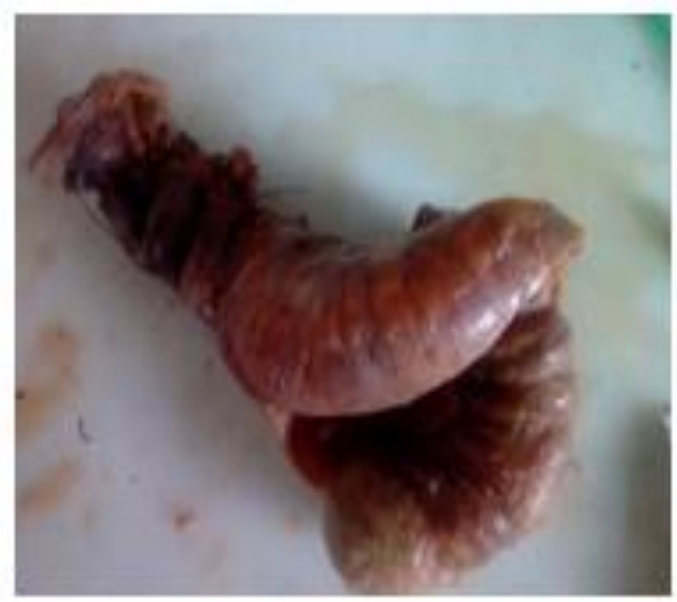

Figure 6

\section{Macroscopic views}

The invaginated part is narrowed alternately with a dilated area the cut involved the invaginated narrowed area and the dilated area of the rest of the mucosa
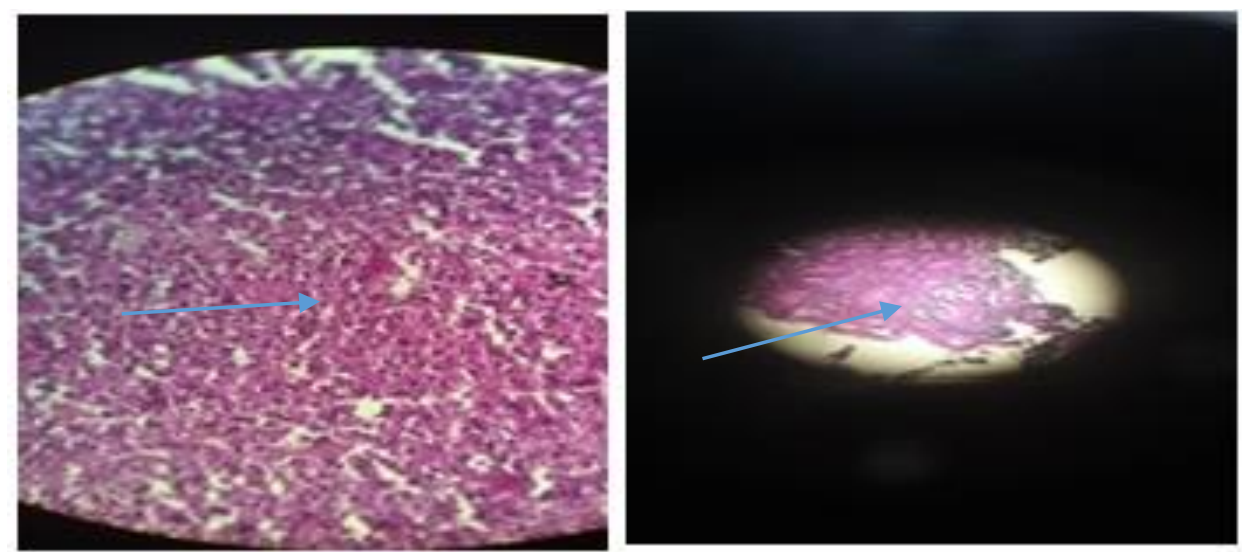


\section{Microscopic views}

The histological sections examined show an inflammatory necrotizing lesion and desquamation of the mucosa replaced by a layer rich in altered and unaltered polynuclear cells and in tissue debris. There are also foci of congestion. This allowed us to conclude that an acute intussusception ischemic necrosis.

\section{Discussion}

During our study period, 2 cases of acute intestinal tracts in adults in 2 years were recorded out of a total of 22 cases of intestinal obstruction, an annual frequency of 1 , cases / year and a frequency of

$0.1 \%$ in relation to intestinal obstruction. Our recruiting case depends on country to country and according to studies. However, the rarity of acute intussusception in adults is also reported in all publications, be they American, European and African, with 22 cases in 18 years (1.2/ year) and 44 cases in 25 years [1], respectively. 76 / year], (2.3).

In Africa, Traore et al reported 41 cases in 28 years, ie 1.48 / year [4]. The average age of our patients was 38 years with extremes ranging from 35 to 42 years. It is therefore the young adult as reported by several authors where this age is between 33 years and 44 years $[4,5]$. The gender ratio is 1 for a man and a woman. All of our two patients, ie 100 percent, were received urgently. In the series by Traore et al, 93\% of patients were admitted in emergency [4]. The patients in our series present with abdominal pain, the same results have been reported by some authors $[6$, 7]. Vomiting was also noted in all patients, these results being higher than those reported in other series $[9,10]$.

Material and gas shutdown was present in both cases, some authors reporting this sign in $25 \%$ to $63 \%$ of cases $[4,5]$. During the physical examination, abdominal palpation is a fundamental element of great diagnostic value; an abdominal mass is palpated in both cases in our series; however, some authors have reported figures ranging from $17.64 \%$ to $58.5 \%[7,8]$. Due to the difficulty of the clinical diagnosis of acute intussusception in adults, radiological investigations play an essential role in the preoperative diagnosis of this pathology. The unprepared abdomen is performed in our two patients, and revealed hail-like hydroaeric levels in one case and mixed hydroaeric levels in one patient.

This result is similar to that of LeBeau et al. [1]. In contrast, in other publications, hydro-aeric levels were present in $50 \%$ to $88 \%$ of cases [6]. Abdominal ultrasound performed in a third of the patients revealed a "target" image in favor of intussusception. There is little demand for this test because first intention. According to the authors the ultrasound image in favor of intussusception as the cause of the obstruction was not suspected in intussusception is found in $50 \%, 85.8 \%$, or even $92 \%$ of cases $[2,9]$. The treatment of intussusception in adults is surgical because of the high incidence of causative organ damage. The choice of surgical method is still influenced by the site, size, cause and viability of the invaginated bowel. Median laparotomy straddling the umbilicus was performed in both patients. The same approach has been reported by several authors $[1,10]$. On exploration, intestinal necrosis was observed in one of the two cases, Bazira reported the same finding [12]. On the other hand, Lebeau et al had reported $50 \%$ necrosis [1]. The ileo-ileal invagination is more common than the ileo-caeco-colic form. Several series have reported a predominance of the ileo-ileal form [4, 12, 13]. Bowel resection was performed in 2 or $100 \%$ patients and we did not perform a simple reduction. These results come close to those of other authors who reported a rate of bowel resection at $95 \%$ of cases versus a simple reduction to $5 \%$ of cases [4.1]. Eihattabi et al reported a $100 \%$ resection rate [7]. In our series, we did not find the tumor cause. Several authors had reported a tumor etiology in $41.4 \%$ to $74 \%$ [4, 1, 7]. M.
Boubbou et al reported a tumor etiology in $100 \%$ of cases [6] The immediate postoperative consequences were simple in our series, on the other hand D. Traore et al reported a mortality rate of 5\% [4].

\section{Conclusion}

Acute intussusception in adults remains a very rare condition, one of the main causes of which is tumor but may also be without an objectified cause. Preoperative diagnosis of intussusception acute in adult's remains delicate, an improvement in diagnostic means in our developing countries is necessary. The ileo-ileal form is more common than the ileo-colic form in adults. Treatment is always surgical in adults, resection was more frequent than simple invagination.

\section{Conflict of interest}

The authors state that there was no conflict of interest in the preparation of this article.

\section{Références}

1. Lebeau R, Koffi E, Diané B, Kouassi JC. [2006] Invaginations intestinales aiguës de l'adulte analyse d'une série de 20 cas. Ann Chir 131:447-450.

2. Zubaidi, A, Alsaif, F, \& Silverman, R. [2006]. Adults intussusceptions: A retrospective review. Disease of colon and rectum. [49]:1546-1551.

3. Barussaud, M., Regenet, N., Briennonx et al. [2006]. Clinical spectrum and surgical approach of adult intussusceptions: a multicentric study; Internationale Journal of colorectal diseases.dec;21[8]:834-839.

4. Traore, D et al. [2012]. Invagination intestinale aigüe chez l'adulte : écueils diagnostiques, morbidité, et mortalité dans un pays en voie de développement : journal de chirurgie viscérale. [149].231-234.

5. Ayite, A.E., Sako, A.S., \& Noma M et al. [1993]. Les invaginations intestinales aigues de l'adulte au Niger. Médecine d'Afrique Noire; 40[12]:746-753.

6. Boubbou, M., Idrissi, M. \& Chraibi et al. [2009]. Invagination intestinale aigueaigüe de l'adulte; feuillets de radiologie;4 9[2].99-104.

7. Eihattabi Khalid et al. [2012]. Les invaginations intestinales chez l'adulte à propos de 17 cas. Pan African Medical Journal, [12]:17.

8. Desai, N., Wayne, M.G., \& Taub P.J. et al. [1999]. Intussusceptions in adults, the Mount Sinai journal of medicine. 1999 [66]:336-340.

9. Dennis, G., Beges, MD., \& Andreas Sandor et al. [1997]. The Diagnosis and management of adult intussusception dennis. The American Journal of Surgery. [173]:88-94.

10. Carneiro, P.M.R., \& Kissusi, M.D et al. [2004]. Intussusception seen at muhimbili National hospital, Dar-ES-Salam .East African Medical Journal, september; 81[9] :439-442.

11. Bazira, L., Ndayisaba, G., Armstrong, O., \& minani MKARayouba, R. [1990]. L'invagination intestinale aigüe. A propos de 18 cas à Bujumbura. Médecine d'Afrique Noire, 37[10]:546-549.

12. Eisen, L.K., Cunningham, J.D., \& Aufese Jr. A.H. [1999]. Intussusception in Adults: institutional review. J Am Coll Surg;[188]:390-395.

13. Ghaderi, H., Jafarian, A., Aminian, A., \& Daryasari, S.A.M. [2010]. Clinical presentations, diagnosis and treatment of adult intussusceptions, a 20 years survey. Int J SURG ;[ 8]:318-322. 
To Submit Your Article Click Here: Submit Manuscript

DOI: $10.31579 /$ jcsr-2021/003 
Ready to submit your research? Choose Auctores and benefit from:

* fast, convenient online submission

* rigorous peer review by experienced research in your field

* rapid publication on acceptance

* authors retain copyrights

* unique DOI for all articles

* immediate, unrestricted online access

At Auctores, research is always in progress.

Learn more www.auctoresonline.org/journals/journal-of-clinical-surgeryand-research 